\title{
Assessment of the "July Effect": outcomes after early resident transition in adult neurosurgery
}

\author{
Bryan A. Lieber, MD, ${ }^{1,2}$ Geoffrey Appelboom, MD, PhD, ${ }^{2}$ Blake E. S. Taylor, BA, ${ }^{2}$ Hani Malone, MD, ${ }^{2}$ \\ Nitin Agarwal, MD, ${ }^{4}$ and E. Sander Connolly Jr., MD ${ }^{2,3}$ \\ 1Department of Neurosurgery, New York University, and ${ }^{2}$ Department of Neurosurgery and ${ }^{3}$ Neurointensive Care Unit, Columbia \\ University Medical Center, New York, New York; and ${ }^{4}$ Department of Neurosurgery, University of Pittsburgh Medical Center, \\ Pittsburgh, Pennsylvania
}

OBJECTIVE Each July, 4th-year medical students become 1st-year resident physicians and have much greater responsibility in making management decisions. In addition, incumbent residents and fellows advance to their next postgraduate year and face greater challenges. It has been suggested that among patients who have resident physicians as members of their neurosurgical team, this transition may be associated with increased rates of morbidity and mortality, a phenomenon known as the "July Effect." In this study, the authors compared morbidity and mortality rates between the initial and later months of the academic year to determine whether there is truly a July Effect that has an impact on this patient population.

METHODS The authors compared 30-day postoperative outcomes of neurosurgery performed by surgical teams that included resident physicians in training during the first academic quarter (Q1, July through September) with outcomes of neurosurgery performed with resident participation during the final academic quarter (Q4, April through June), using 2006-2012 data from the prospectively collected American College of Surgeons National Surgical Quality Improvement Program (ACS NSQIP) database. Regression analyses were performed on outcome data that included mortality, surgical complications, and medical complications, which were graded as mild or severe. To determine whether a July Effect was present in subgroups, secondary analyses were performed to analyze the association of outcomes with each major neurosurgical subspecialty, the postgraduate year of the operating resident, and the academic quarter during which the surgery was performed. To control for possible seasonal trends in certain diseases, the authors compared patient outcomes at academic medical centers to those at community-based hospitals, where procedures were not performed by residents. In addition, the efficiency of academic centers was compared to that of community centers in terms of operative duration and total length of hospital stay.

RESULTS Overall, there were no statistically significant differences in mortality, morbidity, or efficiency between the earlier and later quarters of the academic year, a finding that also held true among neurosurgical subspecialties and among postgraduate levels of training. There was, however, a slight increase in intraoperative transfusions associated with the transitional period in July (6.41\% of procedures in Q4 compared to $7.99 \%$ in Q1 of the prior calendar year; $p$ $=0.0005$ ), which primarily occurred in cases involving junior (2nd- to 4th-year) residents. In addition, there was an increased rate of reoperation (1.73\% in Q4 to $2.19 \%$ in Q1; $p<0.0001$ ) observed mainly among senior (5th- to 7th-year) residents in the early academic months and not paralleled in our community cohort.

CONCLUSIONS There is minimal evidence for a significant July Effect in adult neurosurgery. Our results suggest that, overall, the current resident training system provides enough guidance and support during this challenging transition period.

http://thejns.org/doi/abs/10.3171/2015.4.JNS142149

KEY WORDS seasonal variation; neurosurgery outcome; 30-day outcome; intern; July Effect; ACS NSQIP

ABBREVIATIONS ACS NSQIP = American College of Surgeons National Surgical Quality Improvement Program; CNS $=$ central nervous system; CPT $=$ Current Procedural Terminology; NIS = Nationwide Inpatient Sample; PGY = postgraduate year.

SUBMITTED September 15, 2014. ACCEPTED April 7, 2015.

INCLUDE WHEN CITING Published online December 15, 2015; DOI: 10.3171/2015.4.JNS142149. 
$\mathrm{R}$ ESIDENT participation in surgical procedures is essential for training new surgeons, but it is important to assess whether this necessary educational process adversely affects patient care. In US teaching hospitals, the "July Effect" refers to a hypothesized increase in mortality and morbidity that occurs shortly after 4th-year medical students become 1st-year residents and incumbent residents transition into their next year of training. Patient outcomes, in theory, may temporarily worsen as their new providers adjust to a greater level of responsibility. Large studies in other surgical specialties have demonstrated an increase in adverse outcomes in the late summer, suggesting an association between this transition period and poorer patient care..$^{2,6,9,11,16,19}$ The data are conflicting, however, because other studies have not found evidence for this phenomenon. ${ }^{22}$ Despite great interest in the subject, there has been limited investigation of the July Effect in the field of neurosurgery.

The few studies that have searched for the July Effect in neurosurgery generally did not find evidence for it. However, these studies only examined patients in specific subgroups, such as pediatric or spinal surgery patients, or those with specific conditions such as subarachnoid hemorrhage; no studies to our knowledge have provided data for or against a July Effect in a broad neurosurgical population. ${ }^{4,14,15,20}$ In one important study performed using Nationwide Inpatient Sample (NIS) data from 1998 to 2008 for 850,000 patients, the investigators compared the rates of mortality and complications for patients treated during the month of July to those for patients treated during other months in US teaching hospitals. Among the 4 neurosurgery subgroups covered in that study-nontraumatic hemorrhage, central nervous system (CNS) trauma, CNS tumor, and hydrocephalus-no July Effect was observed, even when data were adjusted for patient demographics and hospital characteristics. ${ }^{21}$ On the other hand, in one study of a general spine population at a single institution, there was a significant increase in the incidence of postoperative infections in the late summer, which the authors suggested may have been related to resident inexperience and/or seasonal changes in microbial flora. ${ }^{8}$ In another large-scale study of patients undergoing procedures for spinal metastases, the adjusted odds of in-hospital mortality and intraoperative complications were higher in July than in other months. ${ }^{5}$ The investigators suggested that this finding, although likely multifactorial, may have been related in part to the relative inexperience of new interns, residents, and fellows, despite more vigilant supervision by attending physicians. ${ }^{5}$

Although informative, many of the previous studies were limited in their assessment of neurosurgical outcomes because, for the most part, they used the internal medicine-focused NIS database. This database not only lacks many surgery-specific variables, such as resident involvement in a particular operation, it also only captures outcomes up until patient discharge. The lack of data on outcomes after the patient leaves the hospital represents a significant drawback of the NIS database, because more than $30 \%$ of adverse events occur within the first 30 days after discharge. ${ }^{3}$

There is a need, therefore, to investigate the possible existence of a July Effect by assessing a large number of outcomes among a broad range of neurosurgical patients, including outcomes after discharge from the hospital. In this study we examined a large patient database for evidence of a July Effect on 30-day outcomes among all adult neurosurgery patients.

\section{Methods \\ Study Design}

For our primary analysis we analyzed postoperative outcomes for neurosurgical patients whose surgical team included residents and compared 30-day postoperative outcomes for neurosurgery performed during the first academic quarter (Q1: July, August, and September) with postoperative outcomes for neurosurgery performed during the final quarter (Q4: April, May, and June). For this analysis we used American College of Surgeons National Surgical Quality Improvement Program (ACS NSQIP) data from 2006 to 2012. Three-month quarters of the academic year were compared because the NSQIP does not record monthly data. The Q1 versus Q4 comparison was chosen because these quarters are the furthest apart in the level of resident training throughout a given academic year and would likely reflect the greatest difference in outcomes should a July Effect exist. Another benefit of not including Q2 or Q3 is that seasonal trends in outcomes during winter months have been described for certain conditions, such as subarachnoid hemorrhage and carcinomatous meningitis, which may have otherwise confounded our results..$^{10,13}$

All neurosurgical cases in the given time intervals for which residents were members of the neurosurgical team were included in the study. Cases in which residents did not provide surgical assistance were excluded; these cases were defined as those in which "Attending Alone" was indicated for the ATTEND variable or 0 (zero) for the PGY (Postgraduate Year) variable. In the NSQIP, the resident level of training is defined by the PGY variable, which codes no resident present as 0 (zero) and then records only the postgraduate year of the highest-ranking resident on the surgical team for the case (PGY1 [intern], PGY 2-4 [junior resident], PGY 5-7 [senior or chief resident]). An operational definition for each of the variables we used is available in the NSQIP User Guide. ${ }^{1}$

Patients with missing values for our selected variables were excluded, as were those who met the exclusion criteria of the NSQIP, such as patients who were brain dead, patients who were younger than 18 years, and patients treated for traumatic injuries. Complete lists of inclusion and exclusion criteria for the database are detailed on the ACS website (https://www.facs.org/quality-programs/acs-nsqip/ program-specifics/inclexcl).

\section{Data Accumulation}

The NSQIP reports 30-day morbidity and mortality data, with a $95 \%$ success rate and a high degree of interrater reliability. ${ }^{18}$ Specially trained surgical clinical reviewers (SCRs) prospectively collect data on randomly assigned, consenting surgical patients from over 500 academic and community hospitals nationwide. Roughly $55 \%$ of hospitals represented in the registry are academic. ${ }^{7}$ For comparison, the American Hospital Association reports 
that there were 5686 hospitals that met their criteria for registration as a hospital facility in 2013 and that 4974 of these were community hospitals (http://www.aha.org/ research/rc/stat-studies/fast-facts.shtml).

\section{Study Outcomes}

Our primary outcome was 30-day mortality in Q1 versus Q4. Secondary outcomes included comparative analyses of morbidity outcomes between Q1 and Q4 as well as each of the 4 academic quarters. Our method for assessing morbidity outcomes was similar to that of the categorization of NSQIP outcomes by Kiran and colleagues, who assessed the effect of residents in a broad range of general surgery cases. ${ }^{12}$

Postoperative complications were classified as surgical or medical. Surgical complications included superficial surgical site infection, deep surgical site infection, organspace infection, wound disruption, bleeding requiring transfusion, failure of graft or prosthesis, and peripheral nerve injury. Medical complications included pneumonia, pulmonary embolism, acute renal failure, stroke, myocardial infarction, sepsis, urinary tract infection, deep venous thrombosis, and thrombophlebitis.

In addition, complications were classified as mild or severe. Mild complications included superficial surgical site infection, peripheral nerve injury, urinary tract infection, deep venous thrombosis, and thrombophlebitis. Severe complications included deep and organ-space surgical site infections, wound disruption, bleeding requiring transfusion, failure of graft or prosthesis, reoperation, pneumonia, pulmonary embolism, acute renal failure, stroke, and myocardial infarction.

Tertiary outcomes included duration of surgery, total length of stay, and postoperative length of stay. In addition, we performed analyses for the following 4 subgroups: patients undergoing any cranial procedure, patients undergoing any spine procedure, patients undergoing any open vascular surgery, and all patients with subarachnoid hemorrhage. Each subgroup was defined by unique CPT (Current Procedural Terminology) or ICD-9 codes (based on the International Classification of Diseases, Ninth Revision) with clear inclusion criteria (Table 1). Further subgroup analyses were performed to compare outcomes among PGY levels of training (1, 2-4, 5-7, and greater than 7 years) of participating residents and fellows, in order to determine whether a July Effect would be limited to cases in which surgical interns (PGY1) operate on patients. Finally, whenever there was a significant finding among the academic cohort of cases with resident participation, we performed a separate analysis on cases without residents present, as a control for potential seasonal variation in certain diseases and outcomes that are independent of resident involvement.

\section{Data and Statistical Analysis}

A direct comparison of baseline characteristics and study outcomes was conducted for Q1 versus Q4, Q1 versus Q2-4, and the entire academic cohort (cases with residents present) versus the community cohort (cases in nonacademic centers without residents). Based on a previous NSQIP study of neurosurgical complications, ${ }^{17}$ univariate analyses were performed on variables that were either demonstrated to be or, based on our background knowledge and medical reasoning, reasonably could be predictors of adverse outcomes in the neurosurgical population. These variables included demographic and preoperative factors such as age, sex, race, spinal versus cranial case, inpatient versus outpatient status, emergency versus nonemergency status of the case, preoperative transfusion with $>4$ units of packed red blood cells, and preoperative sepsis. Other variables included significant comorbidities and patient-specific factors: diabetes mellitus, alcoholism, ventilator dependence, severe chronic obstructive pulmonary disorder (COPD), chronic corticosteroid usage, congestive heart failure, hypertension, renal failure, altered mental status, presence of a brain or spine tumor, prior stroke with and without neurological deficit, and clinical signs or symptoms including dyspnea, paraplegia, quadriplegia, and presence of an open wound. Factors found to be significantly different between Q1 and Q4 as well as basic demographic factors such as age, sex, and race were controlled for in our logistic regression analysis to determine independent predictors of outcomes.

Categorical variables were summarized as frequencies and percentages and were compared by use of the Pearson chi-square test. Quantitative variables were summarized as mean (with standard deviation) or median, as appropriate. Quantitative and ordinal variables were compared by use of the Student t-test. A value of $\mathrm{p}<0.05$ was regarded as statistically significant. Data were analyzed using Stata version 13 (StataCorp).

TABLE 1. The CPT or ICD-9 codes used to create the neurosurgery subgroups used in this study

\begin{tabular}{ll}
\hline \multicolumn{1}{c}{ Subgroup } & \multicolumn{1}{c}{ Codes } \\
\hline Cranial & $\begin{array}{c}21137,21138,21139,21175,21179-21184,21299, \text { and all NSQIP listed CPT codes from 61304 to 62121 (in- } \\
\text { cludes cranial vascular and functional cases) }\end{array}$ \\
\hline Spine & NSQIP CPT codes 63001-63308, 710, 0090, 0092,0095,0096,0163, 0195, 0196, 0202, 22100-22899, \\
& $63709-63710$ \\
\hline Open vascular & $\begin{array}{l}\text { Neck: 35001, 35002, 35005, 35301, 35201, 35800, 37605, 37799, 60600 } \\
\text { Cranial: NSQIP CPT codes 61680-61711 (cranial aneurysm, AVM excision, EC-IC bypass) }\end{array}$ \\
& $\begin{array}{c}\text { Stroke-based on postoperative ICD-9 diagnosis: 430, 433.01, 433.11, 433.21, 433.31, 433.81, 433.91, 434.00, } \\
\text { 434.11, 434.11, 434.91, 436, 431, 432.0, 432.1, 432.9 }\end{array}$ \\
\hline SAH & ICD-9 code 430 (excludes traumatic causes) \\
\hline
\end{tabular}

$\mathrm{AVM}=$ arteriovenous malformation; $\mathrm{EC}-\mathrm{IC}$ = extracranial-intracranial; $\mathrm{SAH}=$ subarachnoid hemorrhage. 


\section{Results}

The ACS NSQIP database for our study period included records from 61,981 neurosurgical cases. Data describing resident involvement were available for 37,135 cases, and these were included in our analysis. Of these, 20,792 cases were community hospital based, without resident participation, and 16,343 were at academic medical centers, with resident participation. Certain baseline demographic variables, as well as preoperative comorbidities, differed significantly between the academic and community groups (Table 2). The case makeup also varied; for instance, cranial cases accounted for only $15.53 \%$ of community cases versus $38.60 \%$ of academic cases $(p<0.001)$. Within the academic group, basic demographic factors and preoperative comorbidities during Q1 were comparable with those during Q4 and Q2-4 (Tables 3 and 4, respectively).

\section{Surgical Outcomes}

In the academic group, there were no significant differences between Q1 and Q4 in terms of mortality $(\mathrm{p}=0.57$, OR 1.09), mild complications ( $\mathrm{p}=0.25$, OR 0.89 ), or medical complications $(\mathrm{p}=0.20$, OR 0.89$)$; however, there was a modest increase in the odds of severe complications $(\mathrm{p}=$ 0.031 , OR 1.16) and surgical complications ( $p=0.03$, OR 1.19) in Q1 compared with Q4. In the community cohort, by contrast, we found no statistically significant difference in mortality or morbidity between Q1 and Q4 (Table 5). When we compared data for Q1 separately with data for each other quarter and analyzed the overall trend, the only variable that showed a significant difference was surgical complications $(\mathrm{p}=0.029)$, although there was a trend toward a significant difference for severe complications $(\mathrm{p}=$ 0.10) (Table 6).

Further analysis showed that a higher rate of intra- and postoperative (within 72 hours) transfusions in Q1 versus Q4 (7.99\% vs $6.41 \%$, respectively; $\mathrm{p}=0.005)$ and an increase in reoperations (2.19\% vs $1.73 \%$, respectively; $\mathrm{p}<$ $0.001)$ that were responsible for the above-noted increases in severe and surgical complications during Q1 (Table 7). In the community cohort there was no difference in the rate of transfusion $(3.04 \%$ for $\mathrm{Q} 1$ vs $3.31 \%$ for $\mathrm{Q} 4, \mathrm{p}=$ $0.50)$ or reoperation $(0.8 \%$ for $\mathrm{Q} 1 \mathrm{vs} 0.7 \%$ for $\mathrm{Q} 4, \mathrm{p}=0.43)$.

\section{Efficiency}

There was no clear evidence for decreased efficiency (as measured by operative duration and total length of hospital stay) in the beginning versus the later portions of the academic year. In fact, the mean duration of operation $(191.52 \pm 123.95$ minutes for Q1 vs $194.28 \pm 120.81 \mathrm{~min}-$ utes for Q4) and total length of hospital stay (5.69 \pm 14.77 days for Q1 vs $5.78 \pm 9.66$ for Q4) were both slightly higher in the final academic quarter than in the first (Tables 8 and 9 , respectively).

\section{Subgroup Analysis}

Neurosurgical Subspecialty

None of the subgroups analyzed (spine, cranial, open vascular, and subarachnoid hemorrhage) exhibited any significantly greater mortality or morbidity (Table 10).
TABLE 2. Demographic characteristics and preoperative comorbidities of community versus academic cases (all quarters) $\dagger$

\begin{tabular}{|c|c|c|c|}
\hline Characteristic & $\begin{array}{l}\text { Community, } \\
n=20,792\end{array}$ & $\begin{array}{l}\text { Academic, } \\
n=16,343\end{array}$ & $p$ Value \\
\hline \multicolumn{4}{|l|}{ Age in yrs } \\
\hline Mean \pm SD & $56.74 \pm 15.03$ & $55.50 \pm 15.34$ & $<0.001$ \\
\hline IQR & $46-67$ & $46-67$ & \\
\hline Male sex & $10,618(51.07)$ & 8334 (50.99) & 0.89 \\
\hline Race & & & $<0.001^{*}$ \\
\hline White & $15,685(75.89)$ & $11,756(71.96)$ & \\
\hline Asian & $231(1.12)$ & $293(1.79)$ & \\
\hline Black & $1477(7.15)$ & $1397(8.55)$ & \\
\hline Hispanic & $1390(6.73)$ & $573(3.51)$ & \\
\hline Unknown & $1884(9.12)$ & $2318(14.19)$ & \\
\hline Cranial cases & $3229(15.53)$ & $6309(38.60)$ & $<0.001^{*}$ \\
\hline Inpatient status & $16,636(80.01)$ & $14,468(80.53)$ & $<0.001^{*}$ \\
\hline Diabetes & $3140(15.10)$ & $2125(13.00)$ & $<0.001^{*}$ \\
\hline Dyspnea & $1492(7.18)$ & $1046(6.40)$ & 0.03 \\
\hline Ventilator dependence & $249(1.20)$ & $452(2.77)$ & $<0.001^{*}$ \\
\hline COPD & $896(4.31)$ & $654(4.00)$ & 0.14 \\
\hline Congestive heart failure & $68(0.33)$ & $55(0.34)$ & 0.88 \\
\hline Hypertension & $9981(48.00)$ & $7322(44.80)$ & $<0.001^{*}$ \\
\hline Renal failure & $26(0.13)$ & $29(0.18)$ & 0.19 \\
\hline Altered mental status & $554(2.66)$ & $743(4.55)$ & $<0.001^{*}$ \\
\hline Stroke w/ deficit & $518(2.65)$ & $909(5.85)$ & $<0.001^{*}$ \\
\hline Stroke w/o deficit & $320(1.64)$ & $361(2.32)$ & $<0.001^{*}$ \\
\hline Paraplegic & $743(3.80)$ & $534(3.44)$ & 0.07 \\
\hline Quadriplegic & $129(0.66)$ & $148(0.95)$ & $0.002^{*}$ \\
\hline Wound infection & $309(1.48)$ & $316(1.93)$ & $0.001^{*}$ \\
\hline Steroid use & $985(4.74)$ & $1193(7.30)$ & $<0.001^{*}$ \\
\hline Required transfusion & $47(0.23)$ & $83(0.51)$ & $<0.001^{*}$ \\
\hline CNS tumor & $1014(5.19)$ & $2724(17.54)$ & $<0.001^{*}$ \\
\hline Emergency cases & $1104(5.31)$ & $1251(7.65)$ & $<0.001^{*}$ \\
\hline Sepsis & & & $<0.001^{*}$ \\
\hline SIRS & $308(1.50)$ & $573(3.52)$ & \\
\hline Sepsis & $118(0.57)$ & $158(0.97)$ & \\
\hline Septic shock & $24(0.12)$ & $43(0.26)$ & \\
\hline
\end{tabular}

COPD = chronic obstructive pulmonary disease; SIRS = systemic inflammatory response syndrome.

* Significant at the 0.05 level.

$\dagger$ Values represent numbers of cases (\%) unless otherwise indicated.

\section{Postgraduate Year of Training}

There were no differences in mortality, medical complications, or mild complications between Q1 and Q4 for cases in which the highest level of resident training was PGY1 (intern), PGY 2-4 (junior resident), PGY 5-7 (senior or chief resident), or fellow (Table 11). However, the PGY 2-4 cohort had a significantly greater rate of surgical complications in $\mathrm{Q} 1$ compared to $\mathrm{Q} 4(8.73 \%$ vs $6.91 \%$, respectively; $\mathrm{p}=0.04$; OR 1.33 ), which was largely attributable to increased intra- and postoperative transfusions (7.32\% for Q1 vs 5.34\% for Q4, $\mathrm{p}=0.025)$. Among the PGY 5-7 cohort, the rate of severe complications was significantly 
TABLE 3. Demographic characteristics and preoperative comorbidities in academic cases: $Q 1$ versus $Q 4 \dagger$

\begin{tabular}{|c|c|c|c|}
\hline Characteristic & Q1, $n=3980$ & $Q 4, n=4383$ & $p$ Value \\
\hline \multicolumn{4}{|l|}{ Age in yrs } \\
\hline Mean \pm SD & $55.58 \pm 15.23$ & $55.51 \pm 15.23$ & 0.82 \\
\hline IQR & $46-67$ & $46-67$ & \\
\hline Male sex & $2068(51.96)$ & $2262(51.61)$ & 0.75 \\
\hline Race & & & $<0.001^{*}$ \\
\hline White & $2794(70.22)$ & $3248(74.17)$ & \\
\hline Asian & $71(1.78)$ & $80(1.83)$ & \\
\hline Black & $322(8.09)$ & $388(8.86)$ & \\
\hline Hispanic & $120(3.02)$ & $146(3.33)$ & \\
\hline Unknown & $672(16.89)$ & $517(11.81)$ & \\
\hline Cranial cases & $1466(36.83)$ & $1754(40.02)$ & $0.003^{*}$ \\
\hline Inpatient status & $3511(88.22)$ & $3920(89.44)$ & 0.08 \\
\hline Diabetes & $536(13.47)$ & $591(13.48)$ & 0.982 \\
\hline Dyspnea & $281(7.06)$ & $277(6.32)$ & 0.18 \\
\hline Ventilator dependence & $95(2.39)$ & $133(3.03)$ & 0.07 \\
\hline COPD & $177(4.45)$ & $176(4.02)$ & 0.33 \\
\hline Congestive heart failure & $15(0.38)$ & $14(0.32)$ & 0.66 \\
\hline Hypertension & $1821(45.75)$ & $1995(45.52)$ & 0.83 \\
\hline Renal failure & $10(0.25)$ & $9(0.21)$ & 0.66 \\
\hline Altered mental status & $152(3.82)$ & $217(4.95)$ & $0.01^{*}$ \\
\hline Stroke w/ deficit & $217(5.80)$ & $260(6.20)$ & 0.46 \\
\hline Stroke w/o deficit & $82(2.19)$ & $96(2.28)$ & 0.77 \\
\hline Paraplegic & $123(3.29)$ & $155(3.69)$ & 0.33 \\
\hline Quadriplegic & $34(0.91)$ & $48(1.14)$ & 0.30 \\
\hline Wound infection & $66(1.65)$ & $82(1.87)$ & 0.46 \\
\hline Steroid use & $283(7.11)$ & $243(7.83)$ & 0.22 \\
\hline Required preop transfusion & $20(0.50)$ & $30(0.68)$ & 0.28 \\
\hline CNS tumor & $664(17.75)$ & $758(18.06)$ & 0.71 \\
\hline Emergency cases & $262(6.58)$ & $369(8.42)$ & $0.001^{*}$ \\
\hline Sepsis & & & 0.99 \\
\hline SIRS & $149(3.75)$ & $161(3.67)$ & \\
\hline Sepsis & $40(1.00)$ & $41(0.94)$ & \\
\hline Septic shock & $11(0.28)$ & $12(0.27)$ & \\
\hline
\end{tabular}

higher in Q1 than in Q4 (16.07\% vs 13.90\%, respectively; $\mathrm{p}=0.03$, OR 1.25 ), which was mainly attributable to an increased rate of reoperations $(2.19 \%$ for Q1 vs $1.73 \%$ for $\mathrm{Q} 4 ; \mathrm{p}=0.001)$.

\section{Discussion}

In this study we analyzed one of the largest prospective databases to assess any impact of the July Effect on 30day outcomes in neurosurgery. Our overall findings demonstrate no clear evidence for an increase in rates of morbidity or mortality during this transition period. Nor did we find evidence for a July Effect among subspecialties or postgraduate levels of the resident involved in the operation, except for a modest (1.58\%) increase in intraoperative transfusions among junior residents (PGY 2-4), and a
TABLE 4. Baseline preoperative demographic characteristics and comorbidities of all academic cases: Q1 versus Q2-4†

\begin{tabular}{|c|c|c|c|}
\hline Characteristic & Q1, $n=3980$ & $\begin{array}{c}\text { Q2-4, } \\
n=12,363\end{array}$ & $p$ Value \\
\hline \multicolumn{4}{|l|}{ Age in yrs } \\
\hline Mean \pm SD & $55.58 \pm 15.23$ & $55.48 \pm 15.36$ & 0.34 \\
\hline IQR & $46-67$ & $46-67$ & \\
\hline Male sex & $2068(51.96)$ & $6266(50.68)$ & 0.16 \\
\hline Race & & & $<0.001^{*}$ \\
\hline White & $2794(70.22)$ & $8962(72.52)$ & \\
\hline Asian & $71(1.78)$ & $222(1.80)$ & \\
\hline Black & $322(8.09)$ & $1075(8.70)$ & \\
\hline Hispanic & $120(3.02)$ & $453(3.67)$ & \\
\hline Unknown & $672(16.89)$ & $1646(13.32)$ & \\
\hline Cranial cases & $1466(36.83)$ & $4843(39.17)$ & $0.008^{*}$ \\
\hline Inpatient status & $3511(88.22)$ & $10,957(88.62)$ & 0.48 \\
\hline Diabetes & $536(13.47)$ & $1589(12.85)$ & 0.982 \\
\hline Dyspnea & $281(7.06)$ & $765(6.19)$ & 0.05 \\
\hline Ventilator dependence & $95(2.39)$ & $357(2.89)$ & 0.09 \\
\hline COPD & $177(4.45)$ & $477(3.86)$ & 0.10 \\
\hline Congestive heart failure & $15(0.38)$ & $40(0.32)$ & 0.61 \\
\hline Hypertension & $1821(45.75)$ & $1995(44.50)$ & 0.83 \\
\hline Renal failure & $10(0.25)$ & $19(0.15)$ & 0.20 \\
\hline Altered mental status & $152(3.82)$ & $591(4.78)$ & $0.01^{*}$ \\
\hline Stroke w/ deficit & $217(5.80)$ & $692(5.87)$ & 0.88 \\
\hline Stroke w/o deficit & $82(2.19)$ & $279(2.37)$ & 0.54 \\
\hline Paraplegic & $123(3.29)$ & $411(3.49)$ & 0.56 \\
\hline Quadriplegic & $34(0.91)$ & $114(0.97)$ & 0.75 \\
\hline Wound infection & $66(1.65)$ & $250(2.02)$ & 0.15 \\
\hline Steroid use & $283(7.11)$ & $910(7.36)$ & 0.60 \\
\hline Required preop transfusion & $20(0.50)$ & $63(0.51)$ & 0.96 \\
\hline CNS tumor & $664(17.75)$ & $2060(17.48)$ & 0.69 \\
\hline Emergency cases & $262(6.58)$ & $989(8.00)$ & $0.003^{*}$ \\
\hline Sepsis & & & 0.81 \\
\hline SIRS & $149(3.75)$ & $424(3.44)$ & \\
\hline Sepsis & $40(1.00)$ & $118(0.96)$ & \\
\hline Septic shock & $11(0.28)$ & $32(0.26)$ & \\
\hline
\end{tabular}

* Significant at the 0.05 level.

$\dagger$ Values represent numbers of cases (\%) unless otherwise indicated.

slight $(0.46 \%)$ increase in the rate of reoperations mainly among senior residents (PGY 5-7) in the early academic months (Q1). These increases associated with the academic year were not paralleled in our community cohort. In addition, there were no significant trends in operative duration or in total hospital length of stay throughout the academic year. Finally, none of our primary or secondary subgroup analyses demonstrated an influence of the July Effect on mortality rates.

In a systematic review of the literature outside the neurosurgical context, 27 studies were found to examine the impact of the July Effect on mortality rates, with 6 studies demonstrating an increase; these 6 studies were generally ranked as high quality. ${ }^{22}$ There are also data from medical 
TABLE 5. Thirty-day postoperative morbidity and mortality: Q1 versus Q4†

\begin{tabular}{|c|c|c|c|c|c|c|c|c|}
\hline \multirow[b]{2}{*}{ Variable } & \multicolumn{4}{|c|}{ Academic } & \multicolumn{4}{|c|}{ Community } \\
\hline & $\mathrm{Q} 1, \mathrm{n}=3980$ & $Q 4, n=4383$ & $\begin{array}{l}\text { Adj } p \\
\text { Value }\end{array}$ & Adj OR & Q1, $n=5123$ & $Q 4, n=5661$ & $\begin{array}{l}\text { Adj } p \\
\text { Value }\end{array}$ & Adj OR \\
\hline Death & $92(2.31)$ & $103(2.35)$ & 0.57 & 1.09 & $77(1.50)$ & $78(1.38)$ & 0.72 & 1.07 \\
\hline Severe complications & $505(12.69)$ & $514(11.73)$ & $0.031^{*}$ & 1.16 & $290(5.66)$ & $333(5.88)$ & 0.68 & 0.97 \\
\hline Mild complications & $187(4.70)$ & $244(5.57)$ & 0.25 & 0.89 & $171(3.33)$ & $177(3.13)$ & 0.53 & 1.07 \\
\hline Surgical complications & $388(9.75)$ & $371(8.46)$ & $0.03^{*}$ & 1.19 & $220(4.29)$ & $260(4.59)$ & 0.54 & 0.94 \\
\hline Medical complications & $289(7.26)$ & $379(8.65)$ & 0.20 & 0.89 & $221(4.32)$ & $248(4.38)$ & 0.85 & 0.98 \\
\hline
\end{tabular}

as well as other surgical specialties-some of which have been extracted from NSQIP - in which investigators found higher mortality rates in July., ${ }^{2,3,5,6,18}$ Although our results do not agree with those of studies focusing on other specialties, our results are consistent with the findings of most other studies that have sought to determine whether a July Effect exists in the practice of neurosurgery. ${ }^{4,14,15,20}$

These findings notwithstanding, in our clinical experi-

TABLE 6. Thirty-day postoperative morbidity and mortality: academic versus community hospitals

\begin{tabular}{|c|c|c|c|c|}
\hline \multirow[b]{2}{*}{ Variable } & \multicolumn{2}{|c|}{ Academic } & \multicolumn{2}{|c|}{ Community } \\
\hline & Adj $p$ Value & Adj OR & Adj $p$ Value & Adj OR \\
\hline Death & 0.69 & & 0.44 & \\
\hline \multicolumn{5}{|l|}{ Q1 (ref) } \\
\hline Q2 & 0.74 & 1.06 & 0.24 & 1.24 \\
\hline Q3 & 0.49 & 0.90 & 0.72 & 1.07 \\
\hline Q4 & 0.55 & 0.91 & 0.70 & 0.94 \\
\hline Severe complications & 0.10 & & 0.88 & \\
\hline \multicolumn{5}{|l|}{ Q1 (ref) } \\
\hline Q2 & 0.05 & 0.87 & 0.85 & 1.02 \\
\hline Q3 & 0.06 & 0.88 & 0.43 & 1.07 \\
\hline Q4 & 0.03 & 0.86 & 0.65 & 1.04 \\
\hline Mild complications & 0.59 & & $0.03^{*}$ & \\
\hline \multicolumn{5}{|l|}{ Q1 (ref) } \\
\hline Q2 & 0.72 & 1.04 & 0.937 & 1.01 \\
\hline Q3 & 0.66 & 1.05 & 0.039 & 1.24 \\
\hline Q4 & 0.19 & 1.14 & 0.53 & 0.93 \\
\hline Surgical complications & $0.029^{*}$ & & 0.32 & \\
\hline \multicolumn{5}{|l|}{ Q1 (ref) } \\
\hline Q2 & 0.01 & 0.82 & 0.71 & 1.038 \\
\hline Q3 & 0.01 & 0.82 & 0.08 & 1.178 \\
\hline Q4 & 0.03 & 0.84 & 0.53 & 1.061 \\
\hline Medical complications & 0.49 & & 0.27 & \\
\hline \multicolumn{5}{|l|}{ Q1 (ref) } \\
\hline Q2 & 0.55 & 1.06 & 0.58 & 1.06 \\
\hline Q3 & 0.23 & 1.11 & 0.08 & 1.19 \\
\hline Q4 & 0.15 & 1.13 & 0.83 & 1.02 \\
\hline
\end{tabular}

ence we have observed that the July transition period is fraught with clinical challenges. As newly minted residents are expected to engage in higher-level clinical responsibilities and perform more advanced surgical techniques, more complications may occur in the absence of proper guidance and heightened vigilance by attendings and more senior residents. Further, although we compared the PGY level of the highest-level operating resident between our Q1 and Q4 groups, in practice the entire resident care team-whose members also experience this transitional period-may also have a major impact on patient care. The etiology of a July Effect, if it exists, is probably not limited to the technical operating proficiency of a single surgical resident, but rather it is a function of the entire care team as they adjust to their new roles and greater responsibilities on a systems level. We were not able to account for the effect on patient care of teams of residents with various levels of experience, however, because a limitation of the

TABLE 7. Breakdown of surgical and severe complications in academic cases: $Q 1$ versus $Q 4 \dagger$

\begin{tabular}{|c|c|c|c|}
\hline Variable & $\begin{array}{c}\text { Q1, } \\
\mathrm{n}=3980\end{array}$ & $\begin{array}{c}\text { Q4, } \\
n=4383\end{array}$ & p Value \\
\hline \multicolumn{4}{|l|}{ Surgical complications } \\
\hline Superficial incisional infection & $41(1.03)$ & $53(1.21)$ & 0.44 \\
\hline Deep incisional infection $\ddagger$ & $25(0.63)$ & $33(0.75)$ & 0.49 \\
\hline Dehiscence/wound disruption $\ddagger$ & $13(0.33)$ & $14(0.21)$ & 0.878 \\
\hline Peripheral nerve injury & $3(0.08)$ & $7(0.16)$ & 0.27 \\
\hline Intraop/postop transfusion $\ddagger$ & $318(7.99)$ & $281(6.41)$ & $0.005^{\prime}$ \\
\hline \multicolumn{4}{|l|}{ Severe complications } \\
\hline Organ-space infection & $19(0.48)$ & $32(0.73)$ & 0.14 \\
\hline Graft/prosthesis failure & $1(0.03)$ & $1(0.02)$ & 0.95 \\
\hline Reoperation & $87(2.19)$ & $76(1.73)$ & $<0.001^{\star}$ \\
\hline Acute renal failure & $4(0.10)$ & $8(0.18)$ & 0.39 \\
\hline Stroke & $51(1.28)$ & $39(0.89)$ & 0.08 \\
\hline Myocardial infarction & $11(0.27)$ & $15(0.34)$ & 0.59 \\
\hline Pneumonia & $69(1.73)$ & $110(2.51)$ & $0.01^{*}$ \\
\hline Pulmonary embolism & $32(0.80)$ & $33(0.75)$ & 0.79 \\
\hline
\end{tabular}


TABLE 8. Trend for operative duration over 4 academic quarters

\begin{tabular}{ccc}
\hline Quarter of Admission & Mean Duration (mins) & SD (mins) \\
\hline Q1 & 191.52 & 123.95 \\
\hline Q2 & 187.92 & 119.38 \\
\hline Q3 & 200.91 & 125.21 \\
\hline Q4 & 194.28 & 120.81 \\
\hline
\end{tabular}

database is that only the highest-level resident involved in any given procedure is recorded. Thus, our PGY-graded subgroup analysis should be interpreted with appropriate caution.

The presence of increased transfusions and reoperation during Q1 in the academic cohort in the absence of a similar parallel trend in the community cohort suggests that this is a genuine finding. However, the significantly different case makeup and demographic characteristics of the community hospital cohort make direct statistical comparisons more difficult. While these findings should be interpreted with caution, the overall trends compared side by side were still helpful in controlling for other general seasonal factors.

Although statistically significant, the finding of a $1.58 \%$ increase in transfusion rate is small, and it is unlikely to have a large clinical impact. It is interesting that an increase
TABLE 9. Trend for total hospital length of stay

\begin{tabular}{ccc}
\hline Quarter of Admission & Mean Length of Stay (days) & SD (days) \\
\hline 1 & 5.69 & 14.77 \\
\hline 2 & 5.22 & 8.62 \\
\hline 3 & 5.63 & 8.11 \\
\hline 4 & 5.78 & 9.66 \\
\hline
\end{tabular}

was more likely in cases involving junior (PGY 2-4) residents, although a lack of additional related data limits our interpretation of the cause. This finding may be associated with a decreased threshold for transfusion among new, overly cautious residents, or it may have occurred because surgeons in training are less efficient in their surgical techniques of achieving hemostasis. In particular, if residents in their new level of training require longer periods for the opening and closing of surgical wounds, a greater amount of blood may be lost (e.g., from scalp vessels).

Similarly, a $0.46 \%$ increase in the reoperation rate is unlikely to be of profound clinical significance, and we are limited in our ability to interpret such a result. However, we did find that this increased rate occurred disproportionately more among the cases involving senior (PGY 5-7) residents and less among the junior residents and interns. While senior residents are often given significant indepen-

TABLE 10. Morbidity and mortality by surgical subgroup $\dagger$

\begin{tabular}{|c|c|c|c|c|}
\hline Category & Q1 & Q4 (ref) & $p$ Value & Adj OR \\
\hline \multicolumn{5}{|c|}{ Spine ( $n=4861, Q 1 n=2399, Q 4 n=2462)$} \\
\hline Death & $27(1.13)$ & $24(0.97)$ & 0.27 & 0.72 \\
\hline Surgical complications & $256(10.67)$ & $222(9.02)$ & 0.07 & 1.20 \\
\hline Medical complications & $96(4.00)$ & $135(5.48)$ & $0.02^{*}$ & 0.72 \\
\hline Severe complications & $270(11.25)$ & $236(9.59)$ & 0.05 & 1.21 \\
\hline Mild complications & $86(3.58)$ & $107(4.34)$ & 0.16 & 0.81 \\
\hline \multicolumn{5}{|c|}{ Cranial $(n=3220, Q 1 n=1466, Q 4 n=1754)$} \\
\hline Death & $59(4.02)$ & $77(4.39)$ & 0.83 & 0.96 \\
\hline Surgical complications & $127(8.66)$ & $140(7.98)$ & 0.24 & 1.17 \\
\hline Medical complications & $185(12.61)$ & $232(13.23)$ & 0.90 & 1.02 \\
\hline Severe complications & $226(15.42)$ & $262(14.94)$ & 0.28 & 1.12 \\
\hline Mild complications & $97(6.62)$ & $132(7.53)$ & 0.61 & 0.93 \\
\hline \multicolumn{5}{|c|}{ Open vascular $(n=744, Q 1 n=330, Q 4 n=414)$} \\
\hline Death & $20(6.06)$ & $42(10.14)$ & 0.06 & 0.56 \\
\hline Surgical complications & $20(8.81)$ & $28(10.53)$ & 0.63 & 0.86 \\
\hline Medical complications & $83(25.15)$ & $107(25.85)$ & 0.90 & 1.02 \\
\hline Severe complications & $97(29.39)$ & $113(29.29)$ & 0.30 & 1.20 \\
\hline Mild complications & $39(11.82)$ & $55(13.29)$ & 0.69 & 0.91 \\
\hline \multicolumn{5}{|c|}{ SAH $(n=132, Q 1 n=57, Q 4 n=75)$} \\
\hline Death & $4(7.02)$ & $12(16.00)$ & 0.10 & 0.31 \\
\hline Surgical complications & $11(19.30)$ & $18(24.00)$ & 0.96 & 0.98 \\
\hline Medical complications & $18(31.58)$ & $31(41.33)$ & 0.44 & 0.73 \\
\hline Severe complications & $24(42.11)$ & $33(44.00)$ & 0.64 & 1.21 \\
\hline Mild complications & $8(14.04)$ & $16(21.33)$ & 0.52 & 0.72 \\
\hline
\end{tabular}


TABLE 11. Thirty-day morbidity and mortality stratified by PGY†

\begin{tabular}{|c|c|c|c|c|}
\hline Variable & Q1 & Q4 & Adj $p$ Value & Adj OR \\
\hline \multicolumn{5}{|c|}{ Interns ( $n=422, Q 1 n=206, Q 4 n=216)$} \\
\hline Death & $4(1.94)$ & $3(1.37)$ & 0.63 & 1.52 \\
\hline Surgical complications & $18(8.74)$ & $15(6.85)$ & 0.42 & 1.38 \\
\hline Medical complications & $8(3.88)$ & $18(8.22)$ & 0.17 & 0.54 \\
\hline Severe complications & $15(7.28)$ & $20(9.13)$ & 0.56 & 0.80 \\
\hline Mild complications & $9(4.37)$ & $12(5.48)$ & 0.92 & 0.96 \\
\hline \multicolumn{5}{|c|}{ PGY 2-4 ( $n=3011, Q 1 n=1420, Q 4 n=1591)$} \\
\hline Death & $31(2.18)$ & $32(2.01)$ & 0.41 & 1.26 \\
\hline Surgical complications & $124(8.73)$ & $110(6.91)$ & $0.04^{*}$ & 1.33 \\
\hline Medical complications & $75(5.28)$ & $122(7.67)$ & $0.01^{*}$ & 0.67 \\
\hline Severe complications & $147(10.35)$ & $165(10.37)$ & 0.80 & 1.03 \\
\hline Mild complications & $58(4.08)$ & $71(4.59)$ & 0.69 & 0.93 \\
\hline \multicolumn{5}{|c|}{ PGY 5-7 ( $n=3209, Q 1 n=1456, Q 4 n=1753)$} \\
\hline Death & $36(2.47)$ & $59(3.37)$ & 0.18 & 0.74 \\
\hline Surgical complications & $166(11.40)$ & $183(10.44)$ & 0.33 & 1.12 \\
\hline Medical complications & $142(9.75)$ & $178(10.15)$ & 0.82 & 1.03 \\
\hline Severe complications & $234(16.07)$ & $245(13.98)$ & $0.03^{*}$ & 1.25 \\
\hline Mild complications & $76(5.22)$ & $115(6.56)$ & 0.18 & 0.81 \\
\hline \multicolumn{5}{|c|}{ Fellows ( $n=226, Q 1 n=99, Q 4 n=127$ ) } \\
\hline Death & $4(4.04)$ & $2(1.57)$ & 0.09 & 9.49 \\
\hline Surgical complications & $13(15.7)$ & $14(12.1)$ & 0.535 & 0.760 \\
\hline Medical complications & $14(16.9)$ & $17(14.7)$ & 0.331 & 0.632 \\
\hline Severe complications & $26(26.26)$ & $24(18.90)$ & 0.10 & 1.81 \\
\hline Mild complications & $10(10.10)$ & $13(10.24)$ & 0.88 & 0.93 \\
\hline
\end{tabular}

dence in deciding the management of patients, junior residents are usually closely watched by attendings, who make many of the major management decisions themselves. Reoperation is often performed to avoid serious sequelae of a condition, and the decision to do so requires experience in balancing the risk of the disease worsening (by not performing a reoperation) with the risk of performing the reoperation itself. In effect, one interpretation of this finding is that the concern for serious sequelae-and thus the likelihood of performing a reoperation-may be greater among senior residents who have a newfound level of responsibility, and who are still becoming seasoned in their ability to balance the risks and benefits of performing a reoperation. Overall, our findings suggest that, even if there is a July Effect, the effect size is probably too small to detect. We can infer that neurosurgery as a field has been successful in overseeing and guiding residents during this critical time period.

This study provides no strong evidence to support the existence of a July Effect that has a significant impact on neurosurgical patient outcomes. The study has several limitations, however. Most significantly, despite the very comprehensive nature of the NSQIP, the database itself has certain limitations. In particular, there is no official designation of academic versus community cases; we used the presence or absence of resident participation in the case as a proxy to distinguish these 2 categories of cases.
Also, NSQIP includes only limited data on endovascular interventions, and as a result our subgroup analysis of subspecialties was restricted to open surgery cases and did not include endovascular and endoscopic cases, exclusions which may have been subject to certain selection biases. While our study had a large overall sample size, it was not sufficiently large enough among peripheral nerve and functional neurosurgery cases to meaningfully perform subgroup analyses in those specialties. Finally, while we were able to determine the highest PGY level of the resident involved in the operating room, this may be a limited assessment of that resident's full involvement in the patient's care and may obscure the impact of a more junior resident in the case.

Future studies are needed with similar, longer-term outcomes after discharge that can incorporate nonteaching hospitals as control groups. Ideally, such investigations would also be able to gauge morbidity and mortality on a month-by-month basis to further control for and identify unknown seasonal patterns. Such studies, however, would not be possible with the NSQIP database, as this information is not included, in order to protect patient privacy. Future work should also be undertaken to determine the clinical impact of preventing interns from taking night call and other similar restrictions, as well as to gauge the degree of resident intra- and postoperative care in a given case. 


\section{Conclusions}

Our study showed no clear evidence for the July Effect in adult neurosurgery. From this finding we can infer that the current system provides enough guidance and support for neurosurgeons in training to ensure that a high quality of patient care is maintained during this challenging transition period.

\section{Acknowledgments}

We acknowledge Dr. Taylor Wilson for notifying us about the work of Rolston et al., ${ }^{17}$ which was helpful in determining the most important morbidity covariates.

\section{References}

1. American College of Surgeons National Quality Improvement Program: User Guide for the 2012 ACS NSQIP Participant Use Data File. Chicago: American College of Surgeons, 2013 (https://www.facs.org/ /media/files/quality\%20 programs/nsqip/ug12.ashx) [Accessed August 4, 2015]

2. Anderson KL, Koval KJ, Spratt KF: Hip fracture outcome: is there a "July effect"? Am J Orthop 38:606-611, 2009

3. Bilimoria KY, Cohen ME, Ingraham AM, Bentrem DJ, Richards K, Hall BL, et al: Effect of postdischarge morbidity and mortality on comparisons of hospital surgical quality. Ann Surg 252:183-190, 2010

4. Bohl DD, Fu MC, Gruskay JA, Basques BA, Golinvaux NS, Grauer JN: "July effect" in elective spine surgery: analysis of the American College of Surgeons National Surgical Quality Improvement Program database. Spine (Phila Pa 1976) 39:603-611, 2014

5. Dasenbrock HH, Clarke MJ, Thompson RE, Gokaslan ZL, Bydon A: The impact of July hospital admission on outcome after surgery for spinal metastases at academic medical centers in the United States, 2005 to 2008. Cancer 118:14291438,2012

6. Englesbe MJ, Pelletier SJ, Magee JC, Gauger P, Schifftner $\mathrm{T}$, Henderson WG, et al: Seasonal variation in surgical outcomes as measured by the American College of SurgeonsNational Surgical Quality Improvement Program (ACSNSQIP). Ann Surg 246:456-465, 2007

7. Garg J, Frankel DA, Dilley RB: Carotid endarterectomy in academic versus community hospitals: the national surgical quality improvement program data. Ann Vasc Surg 25:433441,2011

8. Gruskay J, Smith J, Kepler CK, Radcliff K, Harrop J, Albert $\mathrm{T}$, et al: The seasonality of postoperative infection in spine surgery. J Neurosurg Spine 18:57-62, 2013

9. Haller G, Myles PS, Taffé P, Perneger TV, Wu CL: Rate of undesirable events at beginning of academic year: retrospective cohort study. BMJ 339:b3974, 2009

10. Jakovljević D, Salomaa V, Sivenius J, Tamminen M, Sarti C, Salmi K, et al: Seasonal variation in the occurrence of stroke in a Finnish adult population. The FINMONICA Stroke Register. Finnish Monitoring Trends and Determinants in Cardiovascular Disease. Stroke 27:1774-1779, 1996

11. Jen MH, Bottle A, Majeed A, Bell D, Aylin P: Early in-hospital mortality following trainee doctors' first day at work. PLoS One 4:e7103, 2009

12. Kiran RP, Ahmed Ali U, Coffey JC, Vogel JD, Pokala N, Fazio VW: Impact of resident participation in surgical operations on postoperative outcomes: National Surgical Quality Improvement Program. Ann Surg 256:469-475, 2012

13. Koutras A, Sakellakis M, Makatsoris T, Psachoulia C, Kardari M, Nikolakopoulos A, et al: Seasonal variability in the incidence of carcinomatous meningitis. J Neurosurg 122:543-546, 2015

14. McDonald J, Clarke M: The effect of July admission on inpatient outcomes following spinal surgery. J Neurosurg 18:280-288, 2013

15. McDonald RJ, Cloft HJ, Kallmes DF: Impact of admission month and hospital teaching status on outcomes in subarachnoid hemorrhage: evidence against the July effect. J Neurosurg 116:157-163, 2012

16. Phillips DP, Barker GE: A July spike in fatal medication errors: a possible effect of new medical residents. J Gen Intern Med 25:774-779, 2010

17. Rolston JD, Han SJ, Lau CY, Berger MS, Parsa AT: Frequency and predictors of complications in neurological surgery: national trends from 2006 to 2011. J Neurosurg 120:736745,2014

18. Shiloach M, Frencher SK Jr, Steeger JE, Rowell KS, Bartzokis K, Tomeh MG, et al: Toward robust information: data quality and inter-rater reliability in the American College of Surgeons National Surgical Quality Improvement Program. J Am Coll Surg 210:6-16, 2010

19. Shuhaiber JH, Goldsmith K, Nashef SAM: Impact of cardiothoracic resident turnover on mortality after cardiac surgery: a dynamic human factor. Ann Thorac Surg 86:123-131, 2008

20. Smith ER, Butler WE, Barker FG II: Is there a "July phenomenon" in pediatric neurosurgery at teaching hospitals? J Neurosurg 105 (3 Suppl):169-176, 2006

21. Weaver KJ, Neal D, Hoh DJ, Mocco J, Barker FG II, Hoh BL: The "July phenomenon" for neurosurgical mortality and complications in teaching hospitals: an analysis of more than 850,000 neurosurgical patients in the nationwide inpatient sample database, 1998 to 2008. Neurosurgery 71:562-571, 2012

22. Young JQ, Ranji SR, Wachter RM, Lee CM, Niehaus B, Auerbach AD: "July effect": impact of the academic year-end changeover on patient outcomes: a systematic review. Ann Intern Med 155:309-315, 2011

\section{Disclosures}

No funding or support was provided for this project. None of the authors have a conflict of interest to report. The ACS NSQIP and the hospitals participating in the ACS NSQIP are the source of the data used herein; they have not verified and are not responsible for the statistical validity of the data analysis or the conclusions derived by the authors. This article represents the personal viewpoint of the authors and cannot be construed as a statement of official ACS or ACS NSQIP policy.

\section{Author Contributions}

Conception and design: Lieber, Appelboom, Taylor. Acquisition of data: Lieber. Analysis and interpretation of data: Lieber, Appelboom, Taylor. Drafting the article: Lieber, Taylor, Malone, Agarwal, Connolly. Critically revising the article: Appelboom, Taylor, Malone, Agarwal, Connolly. Reviewed submitted version of manuscript: all authors. Approved the final version of the manuscript on behalf of all authors: Lieber. Statistical analysis: Lieber. Administrative/technical/material support: Connolly. Study supervision: Appelboom, Connolly.

\section{Correspondence}

Blake Taylor, Department of Neurosurgery, Columbia University Medical Center, 630 W. 168th St., Ste. 5-454, New York, NY 10032. email: bet2110@cumc.columbia.edu. 